\title{
Applying Marketing 4.0 in Formal University Enrollment at Vietnamese Universities
}

\author{
Dat Ngoc Nguyen and Loc Xuan Tran
}

\section{ABSTRACT}

\begin{abstract}
Research on applying marketing 4.0 to enrollment at universities will help university walls reach students and students more easily. Therefore, this study is conducted to assess the current status of marketing 4.0 factors related to information quality, the quality of the marketing 4.0 system, and the usefulness of the information provided by the school. Survey results with 250 first-year students on SPSS 20 software have shown that the information quality, system quality, and usefulness of information are all rated as average. The results indicate limitations in marketing 4.0 for formal university enrollment in Vietnam. The study also makes some recommendations to help improve the effectiveness of Marketing 4.0 in fulltime enrollment at universities in Vietnam.
\end{abstract}

Keywords: information adoption model, intention to choose a university, Marketing 4.0, Vietnam.

\section{INTRODUCTION}

After graduating from high school, choosing a university is an important decision for students (Armstrong \& Lumsden, 2000). Life shaping can be determined by university choice decisions (Galotti \& Kozberg, 1996). College choice comes not only from the preferences or pre-existing preferences of parents or students but also from the advertising approach of the university (Armstrong \& Lumsden, 2000). To help students choose the school, universities will advertise and hand out leaflets to attract learners.

In the past many years of advertising, they handed out flyers by mail to candidates before enrolling or completing university entrance exams. In addition, school information or university offers help increase students' chances of college (Armstrong \& Lumsden, 2000). However, research results suggest that manuals and rankings have a minor influence on university choice (Hossler \& Foley, 1995). While these university-supported documents may not be as important as campus visits and parents and students' influence, they play a role in decision-making (Kellaris \& Kellaris, 1988). However, in recent years, direct marketing methods are no longer popular. Still, online marketing forms (Brown, 1996), and the most prominent trend is marketing 4.0. With the advantage of marketing 4.0, universities will deliver advertising messages anytime, anywhere to the university's target audience.

In Vietnam, the application of marketing 4.0 in universities has been powerfully deployed. However, there have not been many studies to evaluate the application of marketing 4.0 in university enrollment in Vietnam. Therefore, this study assessed students' feelings about marketing 4.0 communication activities in university enrollment in Vietnam.

\section{A. Marketing 4.0}

\author{
Submitted : December 02, 2021 \\ Published : February 10, 2022 \\ ISSN: 2507-1076 \\ DOI: $10.24018 /$ ejbmr.2022.7.1.1189 \\ Dat Ngoc Nguyen* \\ Foreign Trade University, Vietnam. \\ (e-mail: nguyenngocdat@ftu.edu.vn) \\ Loc Xuan Tran \\ Foreign Trade University, Vietnam. \\ (e-mail: triads1981@gmail.com) \\ *Corresponding Author
}

Vietnam. The study also makes some recommendations to help improve the effectiveness of marketing 4.0 communication in full-time enrollment at universities in

\section{LITERATURE REVIEW}

Submit your manuscript electronically for review.

Marketing 4.0 is the continuous development of previous generations of marketing and is associated with the 4.0 technology revolution. If Marketing 1.0 revolves around products, Marketing 2.0 revolves around customers, and Marketing 3.0 revolves around people, Marketing 4.0 emphasizes the importance of the human-centered principle for marketing activities and combinations along with elements of the digital age.

Marketing 4.0 is the shift from traditional marketing to modern marketing, applying the quintessence of previous marketing generations flexibly and in line with the rapid development of technology and user trends digital age. Companies need to combine online and offline interactions to attract and maintain strong relationships with customers. Although the digital interaction element is necessary, offline touchpoints become the highlight that makes an essential difference between companies, products/services. Companies must retain their core values and transform quickly to adapt to changing social, market, and technological trends. Besides, honesty becomes the biggest asset of the company because the information on the internet is becoming more and more transparent (Kotler, 2017), users can easily compare and verify data from other sources together. 


\section{B. Applying Marketing 4.0 in Enrollment}

1) The trend of applying marketing 4.0 to regular university enrollment activities of Vietnamese higher education institutions

The financial autonomy mechanism makes public higher education institutions more proactive in recruiting students to ensure revenue. In recent years, Vietnam has begun to grant financial autonomy to universities. Financial autonomy creates conditions for schools and forces schools to face financial problems to ensure a balance of revenue and expenditure. In which, one of the most sustainable and secure sources of income for universities is from students. Therefore, schools actively attract students to enroll through appropriate marketing strategies instead of passively waiting to register as before.

At the same time, the trend of international association and cooperation makes the competition in the higher education market increasingly fierce. Currently, Vietnam has 229 university training programs associated with foreign countries, which is expected to continue to increase. As a result, universities now have to compete with domestic rivals and foreign competitors in the form of joint training and study abroad programs. This makes schools have to become more active and creative in enrollment to increase their school's competitiveness.

Industry 4.0 networks affect all aspects of life, and enrollment is no exception. Firstly, the development of modern technical technologies in Industry 4.0 brings many outstanding solutions and support tools for admissions work, especially in the marketing stage. The devices benefit admissions, such as increasing communication speed and information coverage, supporting target audience analysis, reducing costs, etc. Which school grasps and makes good use of technology quickly? Gain a relative advantage over competitors in the market. Second, along with the increase of internet users in developing the community of "netizens." This young community loves to chat and share information, connecting through the internet, often social networking platforms (Kotler, 2016). Industry 4.0 companies capture the market through this community of "netizens" (Wereda \& Woz'niak, 2019). The student object file has a lot of people belonging to this community. Therefore, universities need to digitize their admissions marketing activities to create more touchpoints in line with the consumption behavior of their target audience.

The effects of the COVID-19 pandemic have entirely changed the way university admissions work. Due to the epidemic, the government was forced to order social distancing and limit activities in large gatherings. Enrollment activities through career counseling and the introduction of training programs at high schools are canceled every year. Universities are forced to think of new methods to respond to the epidemic situation promptly. At this time, marketing 4.0 tools such as live stream answering questions online on social networking platforms, advertising campaigns through excellent videos with high virality become prominent.

For the above reasons, universities in Vietnam are gradually applying 4.0 technologies to their enrollment marketing. Therefore, the next part of the topic will present the situation of implementing marketing 4.0 forms into formal university enrollment activities of educational institutions in Vietnam.

2) The situation of implementing Marketing 4.0 forms into regular university enrollment activities

Marketing 4.0 is the transition from traditional marketing to modern marketing. However, this does not mean completely abandoning old marketing methods, but rather combining the marketing quintessence of previous generations with modern technologies of the digital age. Companies in the 4.0 era need to combine online and offline interactions to attract and maintain strong customer relationships (Kotler, 2016).

Marketing 4.0 is the transition from traditional marketing to modern marketing. However, this does not mean abandoning old marketing methods but rather combining the marketing quintessence of previous generations with modern technologies of the digital age. In addition, companies in the 4.0 era need to connect online and offline interactions to attract and maintain strong customer relationships (Kotler, 2016).

\section{Evaluation of Factors Related to Marketing Communication 4.0 in the Universities}

The study conducted a survey to assess first-year students' characteristics of marketing communication 4.0 in university enrollment. Factors included in the survey include (1) quality of information, (2) quality system, (3) information usefulness. The detailed reviews are as follows:

Information quality factors were rated above average (from 3.52 to 3.87). It can be seen that learners have not appreciated the quality of the information provided by the school. Schools need to improve the data quality further to give students, students, or parents quality information.

TABLE I: THE GENERAL ASSESSMENT OF THE QUALITY OF THE INFORMATION PROVIDED BY THE SCHOOL

\begin{tabular}{cccccc}
\hline & $\mathrm{N}$ & Minimum & Maximum & Mean & Std. Deviation \\
\hline IQ1 & 250 & 1 & 5 & 3.87 & 0.837 \\
IQ2 & 250 & 1 & 5 & 3.83 & 0.835 \\
IQ3 & 250 & 1 & 5 & 3.75 & 0.967 \\
IQ4 & 250 & 1 & 5 & 3.52 & 0.941 \\
IQ5 & 250 & 1 & 5 & 3.75 & 0.903 \\
\hline
\end{tabular}

As for the system quality factor, students' perception of the university's 4.0 marketing system is above average. However, it can be seen that the investment in the university's 4.0 marketing system is still limited. Therefore, there should be better investments in the 4.0 marketing system.

TABLE II: THE GENERAL ASSESSMENT OF THE QUALITY OF THE UNIVERSITY'S 4.0 MARKETING SYSTEM

\begin{tabular}{cccccc}
\hline & $\mathrm{N}$ & Minimum & Maximum & Mean & Std. Deviation \\
\hline SQ1 & 250 & 1 & 5 & 3.85 & 0.947 \\
SQ2 & 250 & 1 & 5 & 3.81 & 0.953 \\
SQ3 & 250 & 1 & 5 & 3.62 & 0.958 \\
\hline
\end{tabular}

The overall assessment of the usefulness of the information provided by the university's marketing 4.0 is also above average (average score from 3.55 to 3.96 ). This result also shows that the content of marketing 4.0 of universities is still limited. Students and students have not appreciated the information provided by the school about the usefulness of the data. 
TABLE III: THE GENERAL ASSESSMENT OF THE USEFULNESS OF MARKETING INFORMATION 4.0 OF UNIVERSITIES

\begin{tabular}{cccccc}
\hline & $\mathrm{N}$ & Minimum & Maximum & Mean & Std. Deviation \\
\hline $\mathrm{IH} 1$ & 250 & 1 & 5 & 3.76 & 0.976 \\
$\mathrm{IH} 2$ & 250 & 1 & 5 & 3.87 & 0.948 \\
$\mathrm{IH} 3$ & 250 & 1 & 5 & 3.96 & 0.895 \\
$\mathrm{IH} 4$ & 250 & 1 & 5 & 3.55 & 1.052 \\
\hline
\end{tabular}

\section{SOLUTION TO IMPROVE INFOMATION QUALITY}

Ensure timeliness and update information: To ensure that information reaches students as soon as they need it, schools need to have a specific communication plan. In it, important milestones need special attention. After the national high school exam, the timelines, such as changing aspirations, announcing the admissions plan, announcing the results, etc., are all announced in advance by the Ministry of Education and Training. The school needs to update promptly and strictly follow to plan communication activities to the children on time, correctly and adequately meeting the needs of each period.

The accuracy and reliability of information is always the first criterion in evaluating the quality of information content of users, so the school needs to promote and strengthen the strict control of the amount of information input information such as the poster's identity, the subject, and language used in the post, the quality of the images displayed, etc., before posting the information on the platform. The management of the fanpage can provide a set of criteria to evaluate information content more quickly and objectively.

Managers should monitor and analyze information flow on university-branded social media sites to track the most viewed posts using tools and software Liked or reshared by their users. From this, brands can identify the points of information that their users find the highest quality. They should then leverage this content to encourage a higher level of engagement on their social media pages, possibly through a giveaway program free library...) to make the content engaging and facilitate the reciprocal connection between the brand and the user. For example, in this study, through surveying and surveying students' opinions, students can see that the content they are most interested in and read the most on the school's fanpage is the posts that are related to the school's campus enrollment mechanism, training program, teaching and learning activities, and club activities at the school, job opportunities.

Regularly checking and updating information on the fanpage also plays an important role in improving users' participation in communication activities. Especially in the context that the epidemic has been causing many negative effects on admissions at universities, updating new information on topics that receive a lot of attention (epidemic, recruitment mechanism, etc.) students, the organization of exams, admissions...) regularly will help increase the level of interest and interaction of users, thereby attracting the attention of many users and indirectly promote communication for the university brand.

\section{SOLUTION TO IMPROVE SySTEM QUALITY}

Improve the access speed of university websites: Schools need to make sure websites are accessible at fast speeds and make sure they are not overloaded or inaccessible. These incidents can affect the school's image, and in the meantime, potential students can also consult information from other universities. In addition, universities need to pay attention to periods of high traffic to ensure the seamless operation of the website.

User-friendly design for smartphones: Considering the recent proliferation of smartphones, the number of users is expected to increase as web browsing increases on the phone becomes routine and the designs become more and more intuitive. Even website design on mobile phones tends to be more interested than the computer version. Besides that trend, phones are also gradually becoming a means for potential students to learn about universities. Therefore, schools need to make sure the format and design of the website are suitable for this device.

\section{SOLUTION TO INCREASE AWARENESS OF INFOMATION USEFULNESS}

To arrange and provide suitable solutions, the author bases on the influence from high to low of three reliable information factors, perception of multidimensional information interaction. To increase awareness of information usefulness, platform providers need to (1) improve the reliability of the information, (2) promote interaction on communication channels, and (3) provide multidimensional information.

\section{CONCLUSION}

Based on the actual survey results, it has been shown that the communication system for marketing 4.0 activities for full-time enrollment at universities in Vietnam is still limited. The factors of information quality, system quality, and information usefulness related to enrollment are still limited. Students who have just entered the school believe that the university provides information that is not quality so that students have enough information to decide to choose their school. In addition, the information system does not work as expected when there is slow access or system failure. Therefore, improving the factors of information quality, system quality, and usefulness of information needs to be done in the future

\section{FUNDING}

This research was funded by the Ministry of Education: "Applying marketing 4.0 in enrollment of formal training systems at higher education institutions in Vietnam", grant number B2020-NTH-05.

\section{CONFLICT OF INTEREST}

Authors declare that they do not have any conflict of interest. 
European Journal of Business and Management Research www.ejbmr.org

\section{REFERENCES}

Armstrong, J. J., \& Lumsden, D. B. (2000). Impact of universities' promotional materials on college choice. Journal of Marketing for Higher Education, 9(2), 83-91.

Brown, S. (1996). Art or science?: Fifty years of marketing debate.

Galotti, K. M., \& Kozberg, S. F. (1996). Adolescents' experience of a lifeframing decision. Journal of Youth and Adolescence, 25(1), 3-16.

Hossler, D., \& Foley, E. M. (1995). Reducing the noise in the college choice process: The use of college guidebooks and ratings. New Directions for Institutional Research, 1995(88), 21-30.

Kellaris, J. J., \& Kellaris Jr, W. K. (1988). An exploration of the factors influencing students' college choice decision at a small private college. College and University, 63(2), 187-97.

Kotler, P., \& Keller, K. L. (2016). A framework for marketing management (p. 352). Boston, MA: Pearson. 